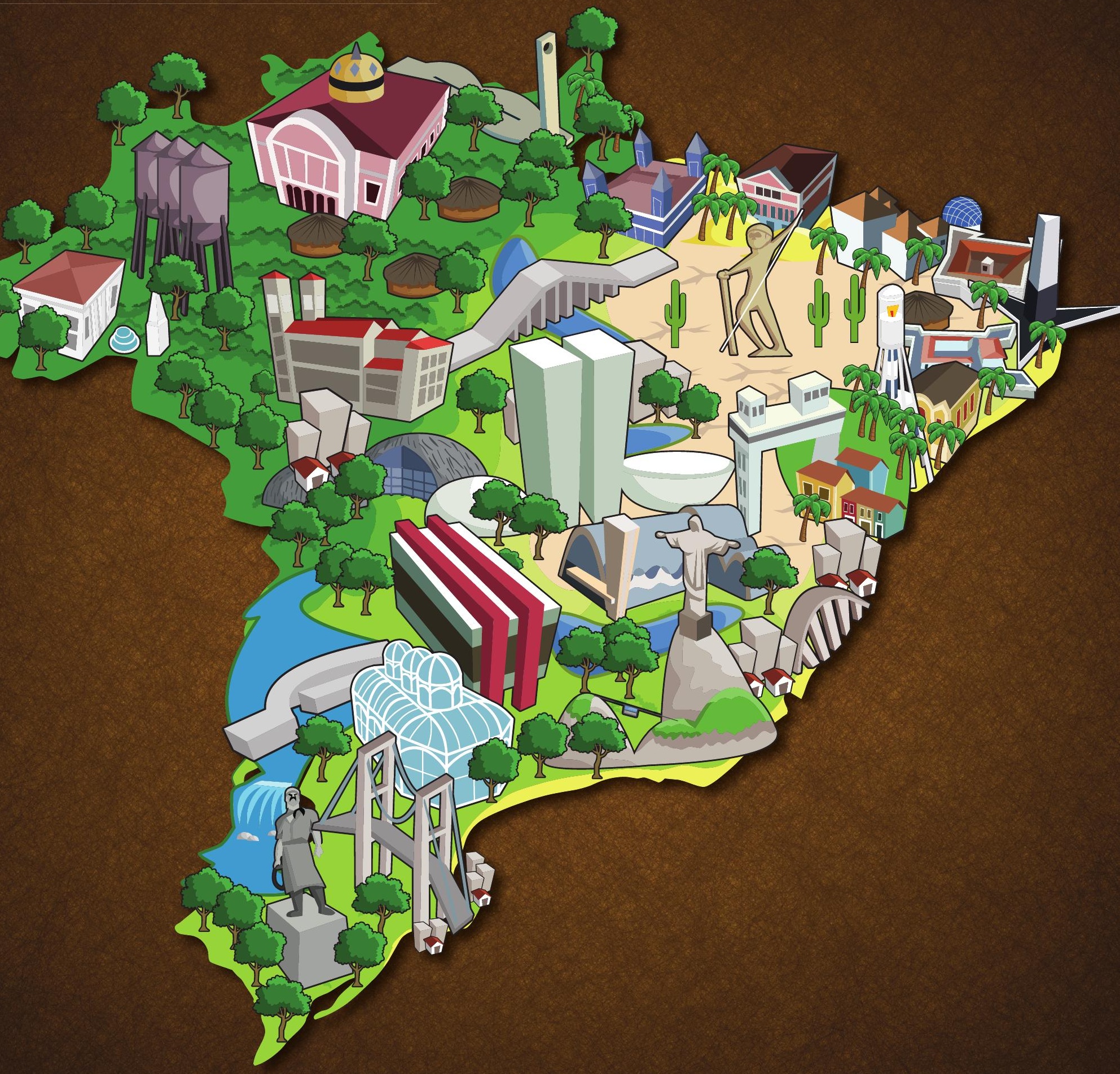




\title{
O PAÍS DO FUTURO \\ PODE SE TRANSFORMAR NO \\ PAÍS DO PASSADO?
}

\author{
APESAR DO CENÁRIO DE DESIGUALDADE, DEIXAMOS DE SER UM PAÍS \\ DE BAIXA RENDA. ENTRETANTO, AGORA CORREMOS O RISCO DE FICAR \\ PRESOS NA ARMADILHA DA RENDA MÉDIA. SERÁ QUE A EAESP ESTÁ \\ PRONTA PARA REPRESENTAR UM PAPEL RELEVANTE NESTA NOVA FASE DO \\ DESENVOLVIMENTO BRASILEIRO?
}

| POR ALKIMAR RIBEIRO MOURA + ANTONIO CARLOS MANFREDINI OLIVEIRA

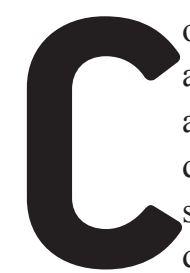
omo se sabe, a dinâmica da economia brasileira até o fim do século XIX foi dominada por ciclos associados ao setor primário. Ao incipiente período do pau-brasil no século XVI, seguiram-se, mais significativamente, o da cana-de-açúcar (XVII), da mineração do ouro (XVIII) e do café (entre o século XIX e o XX). A interpretação mais conhecida desse longo período é a de Celso Furtado, no clássico Formação Econômica do Brasil. Nele, há um papel relevante atribuído ao mercado interno e pouca ênfase no desenvolvimento das instituições e na formação do capital humano.

Os acontecimentos mundiais da primeira metade do século XX submeteram o país a um experimento natural. Uma economia predominantemente agrário-exportadora viu sua receita de exportação cair devido à redução da demanda em seus mercados tradicionais, no período entre a Grande Depressão e o fim da II Guerra Mundial. A escassez de divisas em moeda forte estrangulou as importações e constituiu um estímulo à industrialização substitutiva de bens importados. No plano político, a fragilização das macro-instituições, até então marcadas pelos interesses dos cafeicultores-exportadores, permitiu a transição para o Estado Novo varguista - face política das mudanças na estrutura da economia brasileira.
O Brasil se tornou, especialmente entre 1930 e 1945 , uma economia fechada por imposição de eventos externos, um fechamento acidental. Isso permitiu uma forte ampliação da oferta doméstica de produtos manufaturados, o que contribuiu para um crescimento significativo do PIB. O arcabouço institucional da República Velha foi substituído pelo aparato burocrático do primeiro período Vargas, com relativa modernização da administração e das instituições federais.

O segundo período Vargas (1951 a 1954) e o governo de Juscelino Kubitschek (1956 a 1960) assistiram a um esforço renovado de substituição de importações. O Brasil fechou-se novamente, agora por autodeliberação. O Plano de Metas de Kubitschek é paradigmático deste período. A política econômica passou a ser crescentemente exercida em função dos interesses dos produtores domésticos de manufaturados.

As hipóteses e doutrinas da Comissão Econômica para a América Latina e o Caribe (CEPAL) constituíram o fundamento conceitual das políticas econômicas e essa matriz intelectual continuou influente nos anos seguintes. A FGVEAESP, fundada em 1954, teve importante papel durante os anos do modelo substitutivo de importações, incorporando essas ideias e as propagando, desde então, entre seus alunos. 


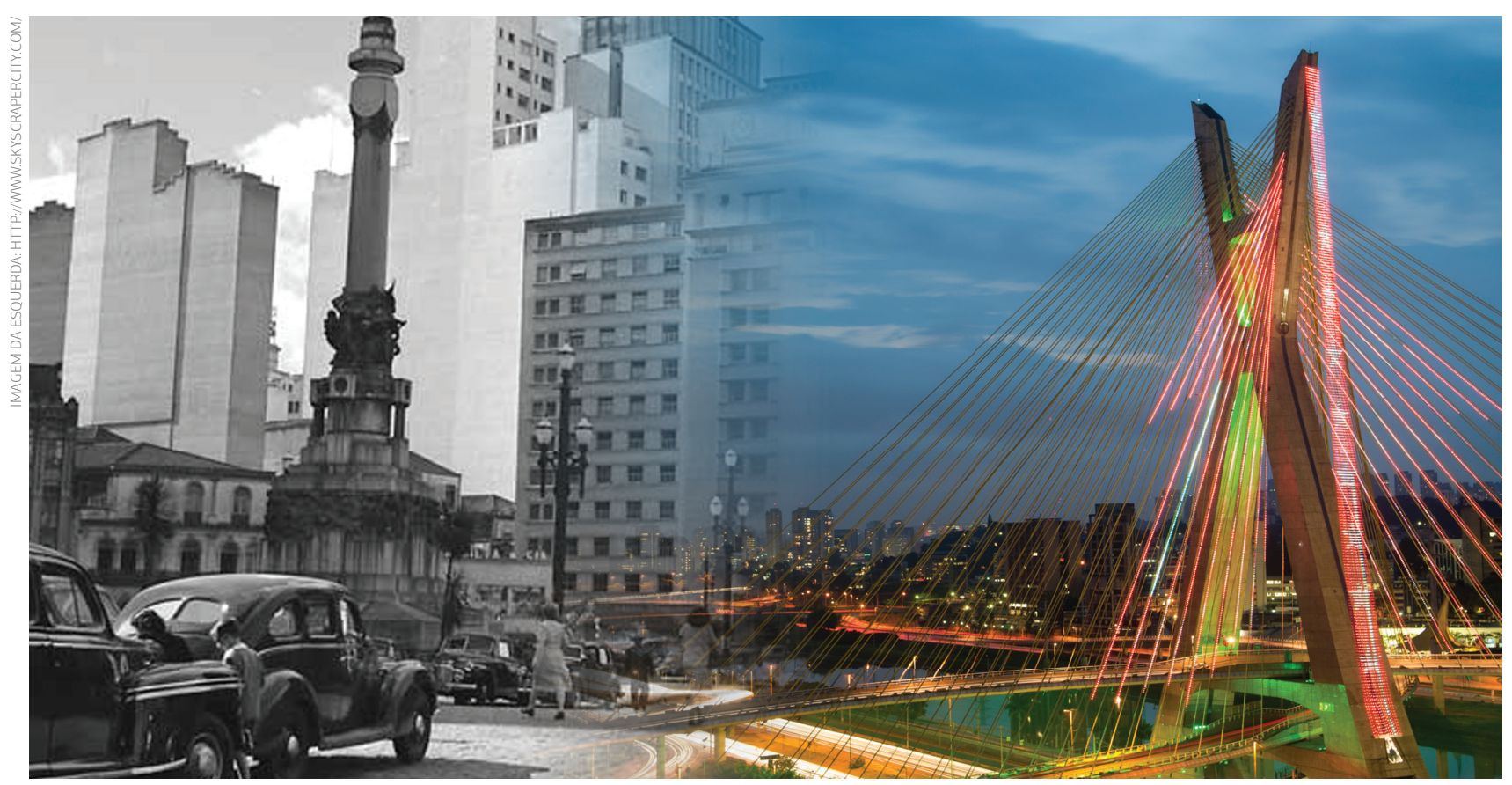

\section{CRISES RECORRENTES NAS DÉCADAS DE 1960 E 1970}

No fim da década de 1950, o crescimento dos gastos públicos e do crédito privado, viabilizados pela expansão monetária, levou a uma crise de financiamento e à intensificação do processo inflacionário, sendo estas duas das causas de uma crise institucional que resultou na ruptura política e na instauração do regime militar.

Em seus primeiros anos, ocorreram algumas reformas liberalizantes sob o Plano de Ação Econômica do Governo (PAEG) e a criação de instituições voltadas à gestão da política monetária e ao fortalecimento do mercado de capitais. Essas e outras mudanças alimentaram um curto período de crescimento intenso: o "milagre econômico", que foi interrompido por erros governamentais e pelos dois choques do petróleo.

A resposta ao primeiro choque do petróleo - representada pelo II Plano Nacional de Desenvolvimento (II PND) — exacerbou a ênfase na substituição de importações, agora voltada ao setor de bens de capital e bens intermediários intensivos em energia (e.g. alumínio, produtos petroquímicos). Com a economia ainda mais fechada, novos riscos de financiamento foram assumidos. $\mathrm{O}$ lado negativo desses riscos não demorou a se materializar, devido ao segundo choque do petróleo e à mudança na política monetária norte-americana, que resultou em drástica elevação da taxa de juros em 1979.
Iniciou-se, então, a crise da dívida externa. Após uma tentativa de ajuste, o Brasil aventurou-se em experimentos heterodoxos, ignorando a crise internacional e gerando resultados que pioraram as contas externas e a taxa de inflação. Premido pela escassez de dólares, o país produziu o segundo maior superávit comercial do mundo no início dos anos 1980 (superado apenas pela Alemanha). As exportações foram favorecidas pela desvalorização cambial, ao passo que as importações sofreram os efeitos de aumento dos preços e rígido controle. Esse ajuste resultou em alta inflação e exacerbação da concentração de renda.

\section{ANOS 1990: ESTABILIZAÇÃO MONETÁRIA, REFORMAS E CRISES EXTERNAS}

Nos anos 1990, surgiram movimentos de abertura comercial ao exterior. O Brasil tentou se inserir no mercado mundial, mas anos de protecionismo cobraram seu preço. $\mathrm{O}$ capital humano revelou-se inadequado, pois, durante as décadas de economia fechada, a educação de qualidade não foi prioridade e as elites a negligenciaram por completo.

Após uma série de experimentos mal sucedidos, o Plano Real, em 1994, promoveu a estabilidade de preços e a reforma monetária. Entretanto, novos choques externos (crises mexicana, asiática e russa), entremeados por reformas incompletas e indisciplina fiscal, forçaram, em 1999, uma reorientação da política econômica em torno do tripé: metas de inflação, câmbio 
flexível e superávits primários. A macroeconomia tornou-se mais sólida. Nos anos seguintes, a economia voltou a crescer, impulsionada pelo aumento da demanda externa por produtos primários (elevação das exportações e dos preços), associada à forte expansão da China. Outro fator determinante foi a vigorosa ampliação no consumo doméstico, decorrente da melhora na distribuição de renda, fruto de programas sociais, do crescimento do PIB e da expansão do crédito.

\section{RECESSÃO DE 2008 E AS RESPOSTAS DA POLÍTICA ECONÔMICA}

A grande recessão de 2008 produziu efeitos devastadores na economia internacional. Suas consequências para o Brasil foram, em certa medida, atenuadas por políticas macroeconômicas compensatórias - redução da taxa básica de juros, atuação agressiva dos bancos públicos na concessão de crédito, diminuição das alíquotas de impostos indiretos e aumento dos gastos públicos -, destinadas a reduzir os impactos negativos sobre a economia.

A recuperação da atividade no período pós-crise parecia rápida e vigorosa, a julgar pela taxa de crescimento real do PIB de 7,5\% entre 2009 e 2010, o que poderia indicar o início de um novo ciclo de expansão. Entretanto, acabou por ser apenas uma fugaz fase expansionista. As expectativas otimistas foram frustradas pelo desempenho medíocre da economia a partir de 2011. Apesar da desaceleração da atividade industrial, o sentimento de perda não é tão grande, já que o nível de emprego continua alto, sobretudo no setor de serviços.

A política macroeconômica centrada nos estímulos à demanda, embora produzisse uma inflexão positiva na trajetória do PIB, não se sustentou. Sinais evidentes de excesso de procura são percebidos no mercado de trabalho, nos déficits crescentes, nos desequilíbrios do setor público e na taxa de inflação. Insistir em mais do mesmo é agravar os problemas macroeconômicos domésticos e confiar na oferta ilimitada de financiamento externo.

\section{NOVAS QUESTÕES, VELHAS RESPOSTAS}

O Brasil deixou de ser um país de renda baixa, mas corre o risco de ficar preso na armadilha da renda média. Décadas de protecionismo associado à industrialização substitutiva de importações pouco mudaram a distribuição de renda, e o desenvolvimento social não acompanhou os padrões internacionais. Nos anos de intensa urbanização e de rápido crescimento, com os interesses nacionais capturados pela manufatura doméstica, a formação de capital humano e as políticas educacionais foram negligenciadas.

\section{COMPARADOS A OUTROS PAÍSES, OS ÚLTIMOS 60 ANOS DO BRASIL NÃO DEVEM SER MOTIVO DE CELEBRAÇÃO}

Atualmente, o Brasil é um país muito diferente daquele de 1954. 60 anos depois, a nação, que sempre se viu como retrato da juventude eterna, caminha rapidamente para a maturidade, vivendo os anos finais de uma transição demográfica desperdiçada entre crises externas e políticas domésticas equivocadas. $\mathrm{O}$ preço desses erros pode se revelar alto demais para as gerações futuras.

A economia é diferente: nos anos 1950, o setor manufatureiro comandava o crescimento e era fonte de aumento de produtividade, ao passo que o setor primário crescia vagarosamente $\mathrm{e}$ era retrógrado. A poupança doméstica era reduzida e os capitais internacionais eram escassos. A inflação permitia ao governo e às elites a extração de poupança para financiamento dos investimentos públicos e privados, concentrando a renda.

Hoje, a indústria encontra-se em virtual estagnação, enquanto a agricultura mostra um vigor notável. Os capitais internacionais são abundantes e tornou-se politicamente inviável extrair poupança interna via inflação. No entanto, a poupança doméstica permanece baixa, mesmo na situação atual, com reduzida taxa de desemprego e quase no pico da população economicamente ativa. O fato é que continuamos a absorver poupança externa, mesmo em anos de pouco crescimento. Além disso, nossa integração global permanece alarmantemente baixa. Não apenas em termos comerciais, mas também em termos de capital humano. O país dos imigrantes já não atrai pessoas em busca de oportunidades como antes. Comparados a outros países, os últimos 60 anos não devem ser motivo de celebração. O modelo que orientou as decisões nessas seis décadas atribuiu um papel fundamental ao mercado interno. Os resultados foram insuficientes para fazer com que o Brasil atingisse níveis de renda per capita e indicadores de desenvolvimento social típicos de país rico.

Isso ainda é possível, mas requer um sentido de urgência que não está presente no país. O Brasil se esforça para se desenvolver, mas lutando as batalhas de ontem, não as de hoje. É preciso superar o passado e se preparar para as batalhas presentes e as que ainda estão por vir.

Em quais batalhas a EAESP vai se engajar? Nas de ontem ou nas de hoje?

ALKIMAR RIBEIRO MOURA > Professor da FGV-EAESP > alkimar.moura@fgv.br ANTONIO CARLOS MANFREDINI OLIVEIRA > Professor da FGV-EAESP > antonio.manfredini@fgv.br 